\title{
Investigations on cycle time reduction, dynamic mechanical properties and creep for rotationally moldable nano composites of linear low density polyethylene and fumed silica
}

\author{
V. G. Chandran, S. D. Waigaonkar \\ BITS Pilani K.K. Birla Goa Campus, Department of Mechanical Engineering, NH-17B, Zuari Nagar, Goa, India, \\ 403726 \\ p2011407@goa.bits-pilani.ac.in,sdw@goa.bits-pilani.ac.in
}

PACS 81.05.Lg

DOI 10.17586/2220-8054-2016-7-4-609-612

Composites of rotationally-moldable linear low density polyethylene (LLDPE) are becoming increasingly popular for rotational molding. In this study, the influence of fumed silica (FS) in pulling force requirement for demolding of rotationally moldable LLDPE is investigated. The dynamic mechanical analysis and creep studies were also performed to ascertain the reinforcement effects of FS in LLDPE matrix.

Keywords: LLDPE, FS, rotational molding.

Received: 31 January 2016

Revised: 9 June 2016

\section{Introduction}

The use of nanoparticles in rotational molding to enhance the melt characteristics and mechanical properties are increasing due to the limited choices of currently-available polymeric materials [1,2]. Linear low density polyethylene (LLDPE) is the most commonly-used polymer for rotational molding. Normally, micro scale additives like anti oxidants, fillers, UV stabilisers, etc., are blended with LLDPE and pulverized to fine powder before molding to obtain the desired products. These additives are generally not nano-scale particles, and hence, do not provide reinforcement to polymer chains. Even though these additives provide desired properties, like UV resistance, reduced product cost, thermal stability, etc, they may adversely affect the mechanical properties [3]. The improvements in mechanical properties, such as tensile strength, impact toughness, creep, stress relaxation, etc. were reported with addition of nano fillers like, organo clays [4], metal nanoparticles [5], titanium oxide [6], zinc oxide [7], calcium carbonate [8] and silica nanoparticles in a polymer matrix [9]. Along with the improvements in mechanical properties, cycle time reduction for the molding process is also highly desired.

From our previous studies, it was observed that the nano-composites of LLDPE-FS up to $4 \mathrm{wt} \%$ FS provided acceptable melt flow characteristics for rotational molding [10]. In this study, nanoparticles of silica up to 4 $\mathrm{wt} \%$ in the form of fumed silica (FS) having primary particle size in the range of 5-50 nm was dry mixed with LLDPE using a high speed mixer and was melt blended and pulverized in a commercial melt extruder and pulverizer. These blends (LLDPE-4\%FS) were rotationally molded in a bi-axial rotational molding machine for studying the dynamic mechanical properties and cycle time. A unique fixture was made to study the mold release force at various temperatures and rates of pulling. The effect on maximum pulling force on commonly used mold materials, aluminum (grade 2024) and mild steel (grade S275), were studied with various LLDPE-FS blends. The PIAT (Peak internal air temperature) during rotational molding was studied using a Templogger, which records and transmits temperature readings wirelessly. The dynamic mechanical properties and viscoelastic creep was studied using DMA Q800 from TA instruments.

\section{Results and discussion}

The influence of FS nano particles, on the dynamic mechanical properties (DMA) viz. storage modulus (E'), loss modulus (E”) and tan delta are given in Fig. 1. With the addition of FS (4\%), an increase of $20 \%$ in storage modulus is observed at room temperature $\left(30^{\circ} \mathrm{C}\right)$, while the loss modulus recorded an increase of $15 \%$. The increasing trend of storage modulus and loss modulus is observed at all temperatures. Two distinct peaks are observed in the loss modulus curve, representing the glass transition temperatures $\left(\mathrm{T}_{g}\right)$. The first peak at $-127^{\circ} \mathrm{C}$ represents the ' $\gamma$ ' $\mathrm{T}_{g}$, which corresponds to small scale movements in polymer chains usually associated with inter- and intramolecular motions. The second peak at $46^{\circ} \mathrm{C}$ represents ' $\alpha$ ' $\mathrm{T}_{g}$, which corresponds to the onset of melting of low molecular weight polymer chains. The peak at $-17^{\circ} \mathrm{C}$ in the loss modulus is analogus to the ' $\beta$ ' $\mathrm{T}_{g}$ observed in low density polyethylene (LDPE). Generally, the $\beta$ transition is not observed in LLDPE. However, due 
to the presence of fumed silica, the amorphous nature is increased in LLDPE, leading to entanglement of polymer chains [11]. The relaxation in polymer chains due to bending and twisting with the presence of FS, analogous to long side branches of LDPE, may be responsible for the presence of this $\beta$ glass transition. At $4 \% \mathrm{FS}$, the concentration the shifts for ' $\alpha$ ', ' $\beta$ ' and ' $\gamma$ ' $\mathrm{T}_{g}$ were not significant as compared to natural LLDPE.

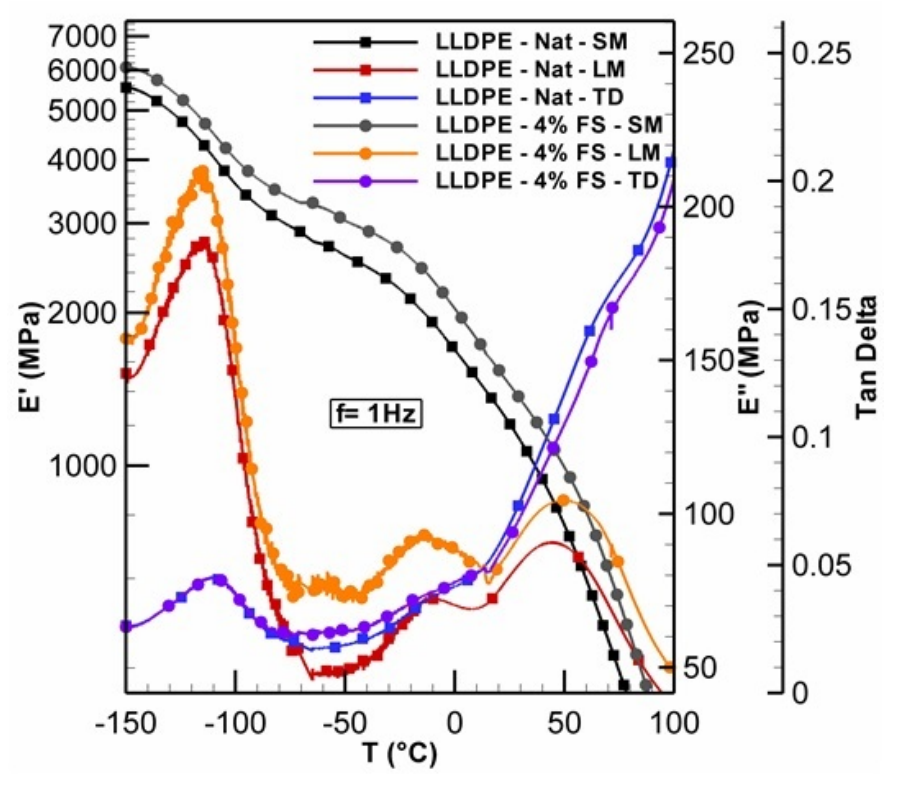

FIG. 1. Visco-elastic properties of LLDPE and LLDPE-4\% FS blends

The proper dispersion of FS in LLDPE is required to achieve good mechanical properties. From our earlier studies, good dispersion was observed by both dry mixing and melt mixing until $2 \%$ FS concentration. Melt mixing is preferred for FS concentrations above $\%$ in LLDPE. The SEM micrograph of LLDPE $-4 \%$ FS, as depicted in Fig. 2, shows good dispersion of FS for the samples tested. With the addition of FS, an increase in melt viscosity due to entanglement of polymer chains was observed, along with improvements in mechanical properties. The improvements in mechanical properties of LLDPE with the addition of FS can be attributed to the restricted movement of polymer chains due to partial entanglement and adhesion of FS to polymer chains. This provides higher resistance to shear in the polymer melt, thus increasing viscosity and polymer chain reinforcement, enhancing the product's mechanical properties. There also exists a structure, consisting of a hydrogen bonding network between the LLDPE chains and silica groups, which leads to improved mechanical properties [12].

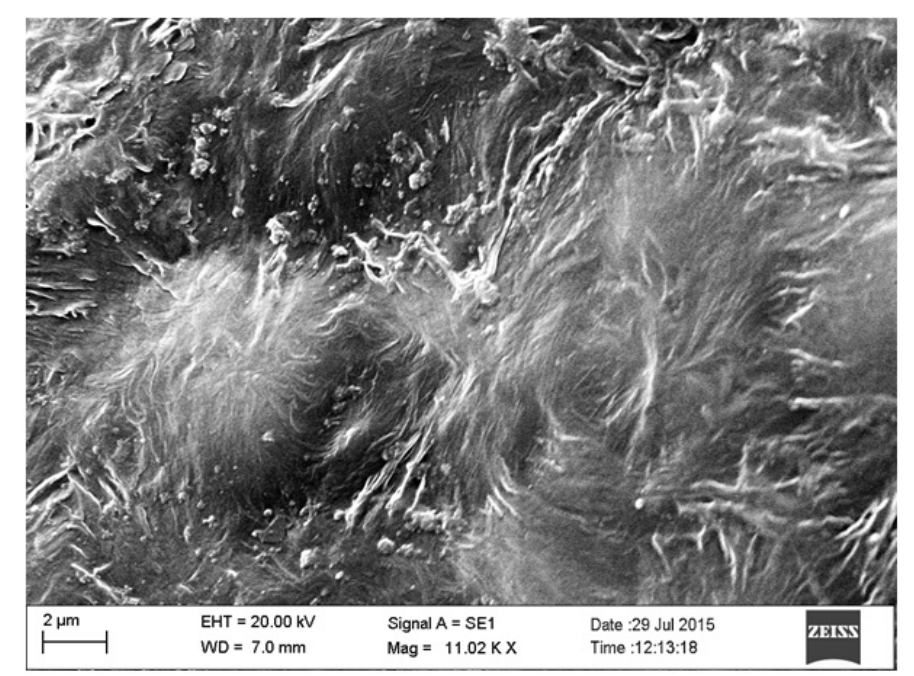

FIG. 2. Dispersion of FS in LLDPE - 4\% FS blend 
For stepped isothermal method (SIM), all the creep tests were done in single cantilever orientation at a constant stress of $0.5 \mathrm{MPa}$. The tests were done at increments of $10^{\circ} \mathrm{C}$ started from room temperature $\left(30^{\circ} \mathrm{C}\right)$ to a maximum of $100^{\circ} \mathrm{C}$ providing a soak time of 5 minutes between every temperature step. The samples were loaded for 180 minutes at each temperature step (a dwell time of 10,000s is recommended by ASTM-D6992) for recording the creep strains. The SIM data were adjusted for thermal expansion and previous history of specimen by the change in temperature. The vertical shifting, rescaling and horizontal shifting were carried out to generate the creep master curves [13]. Creep master curves were generated for $40^{\circ} \mathrm{C}$ and $50^{\circ} \mathrm{C}$ and are shown in Fig. 3. As is readily seen from the graphs, the creep strains tend to decrease with the addition of FS. After an estimated loading of sample for one year $\left(5.26 \times 10^{5}\right.$ minutes) at $50^{\circ} \mathrm{C}$ nanocomposites with $4 \mathrm{wt} \% \mathrm{FS}$, exhibited $13 \%$ reduction in creep strains compared with natural LLDPE. Furthermore, the creep strains were reduced by as much as $13.5 \%$ for $4 \mathrm{wt} \% \mathrm{FS}$, which was predicted to be $5.26 \times 10^{7}$ minutes (around 100 years). The blends did not show significant variation in percentage of strain reduction with temperature. It was observed that, blends with $4 \mathrm{wt} \% \mathrm{FS}$ showed $14 \%$ creep strain reduction at $40^{\circ} \mathrm{C}$ for an estimated loading of 1 year. The measurement of PIAT during rotational molding suggested a possible reduction of PIAT for LLDPE-FS blends. At $4 \%$ concentration, a PIAT of $175^{\circ} \mathrm{C}$ afforded products with good mechanical properties and minimum inner surface blow holes. This represents a reduction in cycle times and energy costs, as a PIAT of $210^{\circ} \mathrm{C}$ is preferred for natural LLDPE.

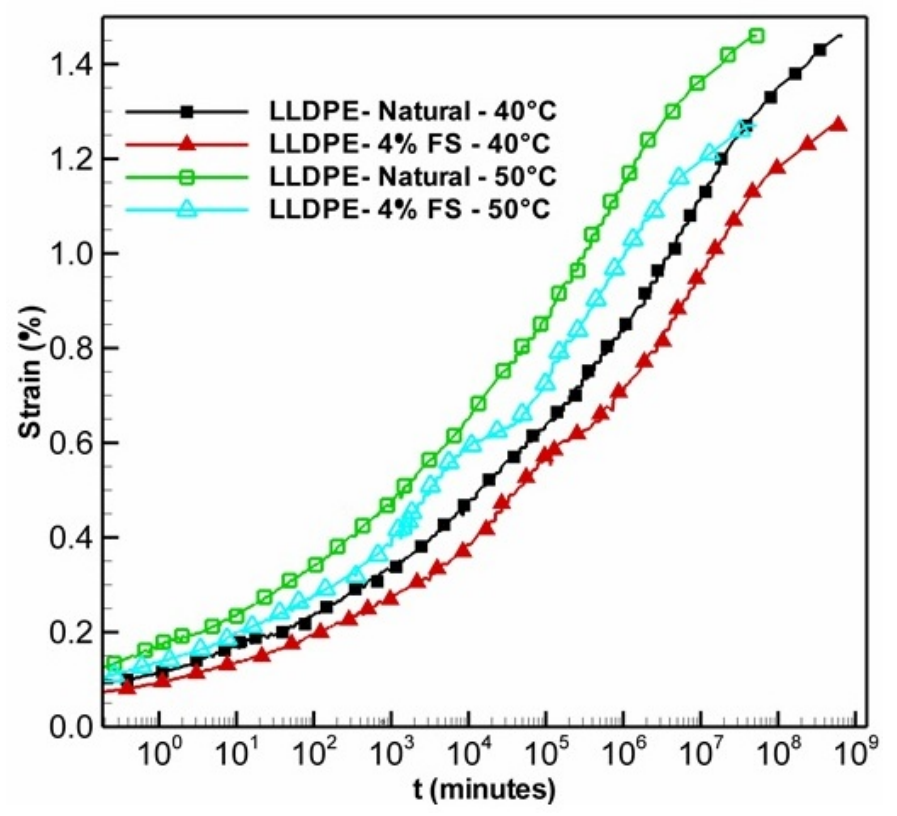

FIG. 3. Creep master curves of LLDPE and LLDPE-4\% FS blends

Another important factor for cycle time reduction is mold release time. The adhesion of polymer to the mold and frictional resistance causes difficulty in the removal of products from a mold. Applying surface coatings and mold release agents reduces frictional resistance, however, applying mold release agents is time consuming and coating will deteriorate over time. Our investigations on pulling force required for removing the product from mold, as measured by a standard UTM using a unique fixture with mold cavity and internal heating is summarized in Fig. 4. It can be observed that the pulling force needed to remove the product from mold reduces with the addition of FS for both mild steel and aluminium molds. The minimum pulling force was observed at $80^{\circ} \mathrm{C}$ and thus it can be considered the ideal temperature to remove the product from the mold. The results show that the use of aluminium mold reduced the pulling force in comparison with that of steel molds at all temperatures. The reduction of pulling force ensures easy removal of the formed product, thereby reducing the cycle time.

\section{Conclusion}

In this study, rotationally moldable grade natural LLDPE and LLDPE-4\%FS blends were used to study the dynamic mechanical characteristics of the parts produced by rotational molding. The improved viscoelastic behavior of LLDPE-4\%FS blends ensures better rigidity and strength for rotomolded products. The reduced creep rates observed in LLDPE- $4 \% \mathrm{FS}$ blends ensure better product life. It was also observed that enhanced mold 


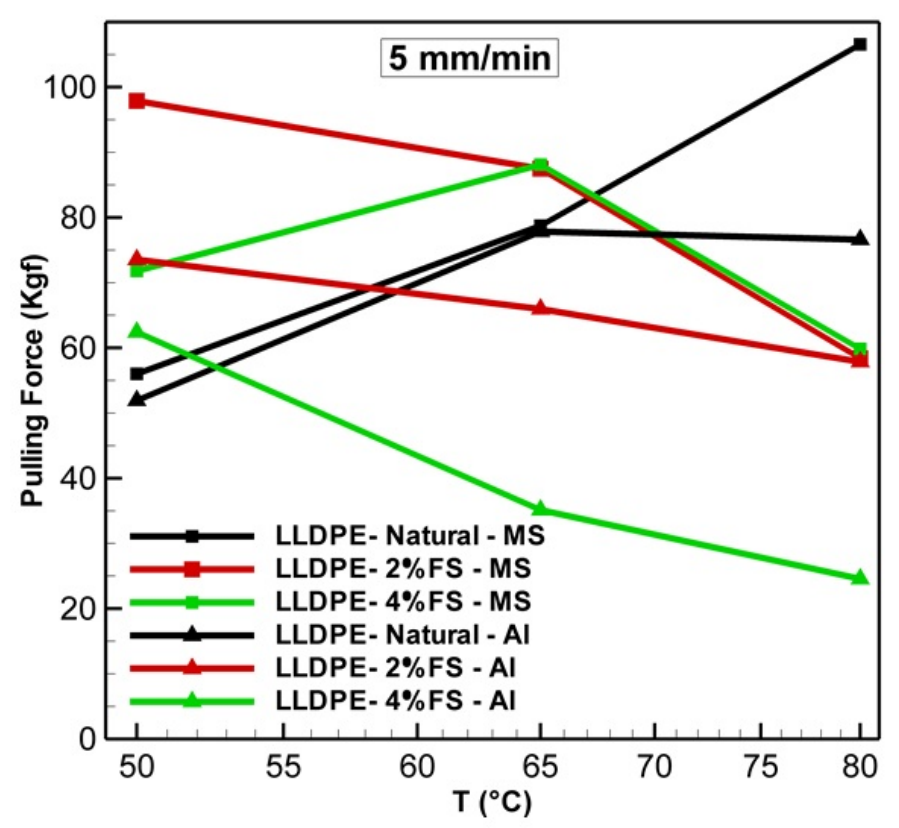

FIG. 4. Variation of pulling force

release and suggested reduction in PIAT considerably reduces the cycle time of the rotational molding process. In conclusion, LLDPE-4\%FS blends make a better substitute for natural LLDPE in rotational molding applications.

\section{References}

[1] Therese L., Harkin-Jones E. An investigation into the relationship between the impact performance of rotationally molded polyethylene products and their dynamic mechanical properties. Polymer Engineering \& Science, 2003, 43, P. 905-918.

[2] Bellehumeur C.T., Tiang J.S. Simulation of Non-Isothermal Melt Densification of Polyethylene in Rotational Molding. Polymer Engineering \& Science, 2002, 42, P. 215-229.

[3] Jancar J., Douglas J.F., Starr F.W., Kumar S.K., Cassagnau P., et al. Current issues in research on structure-property relationships in polymer nano composites. Polymer, 2010, 51, P. 3321-3343.

[4] Cassagnau P. Melt rheology of organoclay and fumed silica nanocomposites. Polymer, 2008, 49, P. 2183-2196.

[5] Molefi J.A., Luyt A.S., Krupa I. Comparison of the influence of copper micro and nano particles on the mechanical properties of polyethylene/copper composites. Journal of Material Science, 2009, 45, P. 82-88.

[6] Esthappan S.K., Kuttappan S.K., Joseph R. Thermal and mechanical properties of polypropylene/titanium dioxide nanocomposite fibers. Materials \& Design, 2012, 37, P. 537-542.

[7] Philippova O., Barabanova A., Molchanov V., Khokhlov A. Magnetic polymer beads: Recent trends and developments in synthetic design and applications. European. Polymer. Journal, 2011, 47, P. 542-559.

[8] Karamipour S., Ebadi-Dehaghani H., Ashouri D., Mousavian S. Effect of nano- $\mathrm{CaCO}_{3}$ on rheological and dynamic mechanical properties of polypropylene: Experiments and models. Polymer. Testing, 2011, 30, P. 110-117.

[9] Cassagnau P., Mélis F. Non-linear viscoelastic behavior and modulus recovery in silica filled polymers. Polymer, 2003, 44, P. $6607-6615$.

[10] Chandran V.G., Waigaonkar S.D. Rheological and dynamic mechanical characteristics of rotationally moldable linear low-density polyethylene fumed silica nano composites. Polymer. Composites. In press, DOI: 10.1002/pc.23496.

[11] Nielsen L.E. Transitions in ethylene polymers. Journal of Polymer Science, 1960, 42(140), P. 357-366.

[12] Dorigato A. Linear low density polyethylene/cycloolefin copolymer blends. Express Polymer Letters, 2010, 5(1), P. $23-37$.

[13] Achereiner F., Engelsing K., Bastian M., Heidemeyer P. Accelerated creep testing of polymers using the stepped isothermal method. Polymer. Testing, 2013, 32, P. 447-454. 